\title{
Rat an experimental model for burns. A systematic review ${ }^{1}$
}

\author{
Rato como modelo experimental de queimadura. Revisão sistemática
}

\author{
Jorge Kiyoshi Mitsunaga Junior ${ }^{\mathrm{I}}$, Alfredo Gragnani' ${ }^{\mathrm{II}}$, Maria Luiza Christóvão Ramos ${ }^{\mathrm{III}}$, Lydia Masako Ferreira ${ }^{\mathrm{IV}}$ \\ I'Graduate student, UNIFESP-EPM, Sao Paulo-SP, Brazil. Acquisition, analysis, interpretation of data and manuscript writing. \\ IIPhD, Associated Professor, Division of Plastic Surgery, UNIFESP-EPM, Sao Paulo-SP, Brazil. Main author. Conception, design, intellectual and \\ scientific content of the study, analysis and interpretation of data, manuscript writing, critical revision. \\ ${ }^{\text {III }} \mathrm{PhD}$, Assistant Medical Center Burns, Sao Paulo Hospital, Brazil. Interpretation of data and manuscript writing. \\ ${ }^{\mathrm{IV}} \mathrm{PhD}$, Chairwoman, Full Professor, Division of Plastic Surgery, UNIFESP-EPM, Sao Paulo-SP, Brazil. Scientific and intellectual content of the study, \\ interpretation of data and critical revision.
}

\begin{abstract}
PURPOSE: To revise and systematize scientific knowledge of the experimental model for cutaneous burns in rats.

METHODS: A bibliographical review from 2008 up to January 2011 in PubMed, EMBASE and LILACS was undertaken. Were used the keywords: animal models, burns and rats. 221 studies were identified, and 116 were selected.

RESULTS: It was found that: 54/86 (62.7\%) had third degree burns; $55 / 73$ (75.3\%) studied the back; $45 / 78(57.6 \%)$ used heated water and 27/78 (35.9\%) incandescent instruments; 39/78 (50\%) studied systemic effects; 22/71 (31\%) used ketamine associated with xylazine; 61/64 (95.3\%) performed depilation with appropriate equipment; 36/72 (50\%) used microscopy; more than 50\% did not describe analgesia or antibiotics during the postoperative period; in 42/116 (36.2\%) postoperative fluid therapy was performed; and the time interval after the burn, up to the beginning of the results analysis varied from $7 \mathrm{~s}$ up to four weeks. Legislation issues on burn experiments are discussed.

CONCLUSION: The hot water was the main method to induce burns those of third degree on the back, with anesthesia using ketamine and xylazine, after depilation. These were evaluated microscopically, without using analgesia or an antibiotic during the postoperative period. The studies were not very reproducible.
\end{abstract}

Key words: Models, Animal. Burns. Skin. Review. Rats.

\section{RESUMO}

OBJETIVO: Revisar e sistematizar o conhecimento científico do modelo experimental em queimadura da pele em ratos.

MÉTODOS: Revisão da literatura foi realizada de 2008 a Janeiro de 2011 na PubMed, EMBASE e LILACS. Os descritores usados foram: modelo animal, queimadura e ratos. 221 estudos foram identificados e 116 foram selecionados.

RESULTADOS: Foi encontrado que: 54/86 (62,7\%) tinham queimadura de terceiro grau; 55/73 (75,3\%) estudaram o dorso; 45/78 (57.6\%) usaram líquido aquecido e 27/78 (35,9\%) usaram instrumento incandescente; 39/78 (50\%) estudaram efeitos sistêmicos; 22/71 (31\%) usaram ketamina associada a xilazina; 61/64 (95,3\%) realizaram depilação com equipamento apropriado; 36/72 (50\%) usaram microscopia; mais de 50\% não descreveram uso de analgésicos ou antibióticos durante o período pós-operatório; em 42/116 (36,2\%) foi realizada reposição hídrica pós-operatória; e o intervalo de tempo após a queimadura e a análise variou de 7s a quatro semanas. Aspectos legais sobre experimentos em queimaduras foram discutidos.

CONCLUSÃO: Líquido aquecido foi o principal método para induzir queimadura de terceiro grau no dorso do animal, com anestesia usando quetamina e xilazina, após depilação, avaliados por microscopia, sem uso de analgesia ou antibióticos. Os estudos não são reprodutíveis.

Descritores: Modelos Animais. Queimaduras. Pele. Revisão. Ratos. 


\section{Introduction}

The mortality rate in burns during the last decades is declining due to the development of clinical treatment of this severe trauma ${ }^{1}$. However, in the United States of America (USA) there are still more than a million cases of burns per year ${ }^{2}$, resulting in more than half a million cases being treated in emergency room ${ }^{3}$. According to the World Health Organization (WHO), around 300.000 deaths are estimated per year world wide due to burns ${ }^{4}$.

Burns are responsible for many pathophysiological changes $^{5-7}$, representing a severe form of trauma ${ }^{7,8}$ which may result in complications such as: a rise in infection rate, an increase in hospital stay, prolonged time of inactivity and also a greater mortality rate. Among other changes, concerning reintegration into society post discharge, psychological changes are also observed such as post-traumatic stress syndrome in the cases of victims of extensive burns s, $^{5,10}$.

Even knowing that there are many advances in knowledge occurring within the care of burns, treatment is still far from ideal, because of lack of evidence-based medicine in burns ${ }^{11}$. Damages caused by burns are a matter of public health in less developed countries (LDCs) and also in developing countries. Many have inadequate infrastructure and research centers to undertake proper care concerning the treatment of burns ${ }^{12,13}$.

Burns of large surface area may turn into a systemic problem, affecting a diverse range of organs and generating high levels of morbidity and mortality ${ }^{14}$. There is a hypercatabolic state ${ }^{15}$ and immunosuppression resulting in an increased risk of cachexia and infection ${ }^{1}$. There is an intense and continuous inflammatory process, coordinated by hormones, cytokines and acute phase proteins, which can continue until the definitive closure of the lesions ${ }^{17}$.

In order to enhance the knowledge of burn physiopathology and study possible therapeutic agents, diverse experimental models may be applied: a) cell and tissue culture research regarding the action mechanisms of therapeutic agents and also research regarding burn tissue substitutes; b) animal studies concerning varying sizes, shapes and body mass in order to evaluate therapeutic agents' efficacy and also to allow the study of biological phenomena in vivo related to burns - and following these stages, allow for clinical studies to be performed on humans ${ }^{18}-$ with safety aspects verified in pre-clinical experiments on animals ${ }^{1}$.

Rats and humans share many physiological and pathological characteristics in many systems and organs that have been already extensively documented ${ }^{20}$. Besides this, rats are small in size, cheap, easy to obtain and maintain and reproduce quickly. These characteristics make rats an ideal animal as a model for experimentation ${ }^{20}$.

\section{Methods}

The research was approved by the Ethics Research Committee of the Federal University of Sao Paulo with protocol number 1556/10. Scientific papers were studied regarding our model and methodological approach for the period from January 2008 up until January 2011. The research was performed using databases: PubMed, EMBASE and LILACS. The main keywords used were "animal models, burns and rats". This was done in accordance with the DeCS/MeSH version and by also crossing information using the keyword "and".

By applying such norms and procedures, 221 papers were identified. In PubMed there were 159 articles under the quoted parameters. Of this total, however, excluded were: a) 11 articles considering esophagus burns, b) 12 articles dealing with burns to the eye, c) five relating to inhalation burn lesions, d) nine articles considering hemorrhagic shock, e) one article which used the pig as the experimental animal, f) 45 non-experimental studies - resulting in selecting 76 articles for research.

Considering EMBASE, 60 studies were found. However, one was excluded due to esophagus burn, 15 were also excluded due to eye burns, another due to inhalation burn lesions, and another five were excluded as they were non-experimental studies, resulting in 38 cases being selected. Regarding LILACS, only two studies were encountered and none excluded. Finally, the research review was undertaken using 116 studies and all specifically dealing with rats as a model concerning skin burns.

The methodology used in these studies was very heterogeneous. As a result, it was not possible to determine all data regarding each of the studies. This was due to the absence of details in the methodology or in other sections of the text. Therefore, it was not possible to perform a complete statistical analysis of the data and the results presented are relative numbers.

The research was organized according to the methodology of how the burn could be produced on the rats' skin respecting extension and depth of burn, considering the causal agent of the burn, temperature and agent exposure time, parts of the body where the burns were located, specific local effects or systemic effects. Anesthetics used were also considered for determining research results, including the preparation of the area of the body, the laboratorial analysis and its techniques applied to the experiments, analgesia and fluid therapy during the post-op period, the use 
of antibiotics and the time interval following the burn up until commencement of the laboratorial analysis.

Considering that some articles had as their objective to evaluate the biological processes related to burns through: a) histological, b) protein or c) genetic analysis, these were correlated to lesions caused in animals researched with: a) light microscopy, b) imuno-histochemistry, c) ELISA, d) Western-Blot, e) electrophoresis, and f) PCR.

\section{Results}

\section{The technique of generation burn surface}

The techniques used to generate burn surfaces for experimental model included heated water, incandescent instruments and electricity.

Of the 116 selected studies, 78/116 (67.24\%) described the burns model. Studies with heated water were represented in $45 / 78$ (57.6\%). Incandescent instruments were mentioned in 27/78 (34.6\%). Electricity and paraffin in 5/78 (6.4\%), while Cobalt was cited in $1 / 78(1.2 \%)$. Heated water model was made in a recipient that had its liquid heated up to the determined temperature fixed by author.

\section{Size and thickness of burn}

Of the 116 studies, 86/116 (74.1\%) described the generation of superficial and deep wounds. In 2/86 (2.3\%) first and second degree burns were identified; in 30/86 (34,9\%) second degree burns were mentioned; while in 54/86 (62.8\%) third degree burns were described. The 30/116 (25.8\%) remaining provided no details regarding the resulting degree of burn. The size of the burn relative to the total body area presented a wide variation, with values ranging from $1 \%$ up to $60 \%$ of body surface area. The burnt area obtained via the use of instruments was influenced by the size of the tip of the instrument and the amount of time the instrument was exposed to the anatomic area of the animal.

Second degree burns were distributed as follows: in six studies the defined area were $1 \%, 3 \%, 10 \%, 20 \%, 30 \%$ and $60 \%$ respectively. In other three studies the areas were the same size as the tip of the instrument $\left(200 \mathrm{~mm}^{2}, 225 \mathrm{~mm}^{2}\right.$ and $\left.500 \mathrm{~mm}^{2}\right)$. In other four cases the size of the tip of the instrument was 2.5 $\mathrm{mm}$ and $20 \mathrm{~mm}$. The formula used to calculate the areas was as follows: [TBSA $\left(\mathrm{cm}^{2}\right)=9.1 \mathrm{BW}^{2 / 3}$ ] where 9.1 is a fixed attributed value and "BW" represents the weight of the animal in grams ${ }^{21}$. The area was calculated in only one article while the other articles provided no descriptions.

Third degree burns presented in 40 studies and the area varied from $2 \%$ to $60 \%$; in five studies the area was described as the size of the tip of the instrument $\left(6 \mathrm{~mm}^{2}, 150 \mathrm{~mm}^{2}, 225 \mathrm{~mm}^{2}\right.$, $800 \mathrm{~mm}^{2}$ and $1000 \mathrm{~mm}^{2}$ ); two articles mentioned the diameter of the tip of the instrument ( $6 \mathrm{~mm}$, and $15 \mathrm{~mm})$.

\section{Temperature and length of exposure}

The temperatures quoted in the studies presented a variation from $52.5^{\circ} \mathrm{C}$ up to its incandescent state when the material acquired a red color.

The length of exposure to the source of heat varied from a touch with the incandescent instrument up to 15 minutes. Regarding the use of hot water, the temperature varied from $60^{\circ} \mathrm{C}$ to $100^{\circ} \mathrm{C}$, measured with a thermometer. Using incandescent instruments, the temperature varied from $70^{\circ} \mathrm{C}$ to incandescent and length of exposure from touch to $45 \mathrm{~s}$.

\section{Location of burn}

Of the 116 studies, 73/116 (63\%) described the location or anatomical region of the burn. By doing so, 55/73 (75.3\%) used exclusively the back as a chosen location of the burn; 18/73 (24.6\%) used some other location or a combination of locations that included the back: scapular, temporal, extremities, lumbar and abdomen. In other studies, 43/116 (37\%) did not mention the location of the wound.

\section{Effects}

Of the total of 116 studies, 78/116 (67.24\%) described the effects of burns. Therefore, 39/78 (50\%) related local effects; systemic effects were also described in 39/78 (50\%); the remaining cases, 38/116 (32.76\%) had no indication concerning the effects.

\section{Anesthetics}

Of the 116 studies, 71/116 (61.2\%) mentioned the use of anesthetics. Ketamine and Xylazine were used in 22/71 (31\%) of the studies; Pentobarbital in 16/71 (22.5\%); Isoflurane in $10 / 71(14.1 \%)$; Ketamine in 5/71 (7.1\%); Thiopental was used in 3/71 (4.2\%); Ether 2/71 (2.8\%); Halothane 2/71 (2.8\%); Urethane with Chloralose 2/71 (2.8\%); Urethane 2/71 (2.8\%); Barbitone 1/71 (1,4\%); Ethylcarbamate with Alphachlorose 1/71 (1.4\%); Halothane with Isoflurane 1/71 (1.4\%); Pentobarbital with Ketamine 1/71 (1.4\%); Ketamine with Xylazine added to Thiopental 1/71 (1.4\%); Ketamine with Xylocaine 1/71 (1.4\%); Ketamine with Thiopental 1/71 (1.4\%). The remaining 45/116 (38.8\%) did not mention the type of anesthetic used in the research. 


\section{Depilation}

Of the 116 studies, 64/116 (55.1\%) related to the use of depilation of the location of burn. Animals who had their hair removed with a shaver represented $61 / 64(95.3 \%)$ of the studies. One study, 1/64 (1.5\%) stated that sodium sulphite was used as depilator. Two cases or 2/64 (3.1\%) mentioned that no depilation had been performed while in the remaining cases 52/116 (44.8\%), there was no indication whether depilation took place or not.

\section{Laboratorial techniques applied to study burn samples}

When analyzing burn area some options were specified as microscopy, immunohistochemistry, ELISA, Western-Blot, PCR and electrophoresis. Of the 116 studies, 72/116 (62\%) mentioned the use of at least one form of the above options. Microscopy was found to be the most widely used form.

\section{Analgesia during the postoperative period}

Of the 116 studies, 17/116 (14.6\%) mentioned the use of analgesia during the postoperative period. Animals that received analgesia during the postoperative period represented 13/17 (76.4\%); 4/17 (23.5\%) did not use any analgesics during the postop period. The remaining 99/116 (85.3\%) made no mention of the use of analgesics. Of the group that used analgesics, 10/13 (76.9\%) used Buprenorfine; 1/13 (7.6\%) used Dolantine; $1 / 13$ (7.6\%) used Dimenidrinate; while 1/13 (7.6\%) used Tenoxicam.

\section{Fluid therapy during the postoperative period}

Of the 116 studies, 43/116 (37\%) mentioned fluid therapy during the post-op period. The animals that went through a period of post-op fluid therapy consisted of $42 / 43$ (97.7\%). In these cases, the formula for the infusion presented a large variation. Only 1/43 $(2.3 \%)$ did not use post-op fluid therapy. The remaining 73/116 $(45.3 \%)$ made no mention of using fluid therapy post operatively.

\section{Topical antimicrobial}

Of the 116 studies, 9/116 (7.7\%) mentioned topical antimicrobial, 107/116(92.3\%) no mentioned topical antimicrobial. It was found that $7 / 9(77.7 \%)$ used and 2/9 (22.3\%) made no use of topical antimicrobial. Of the $7 / 9(77.7 \%)$, three used $1 \%$ silver sulphadiazine, while the time of use and changing period was not described. In one case, a non-specific antimicrobial ointment and an isotonic saline solution was used, another made use of $1 \%$ silver sulphadiazine with chitosan gel, while one used mupirocin.

Post-burn time interval

Of the 116 studies, 94/116 (81\%) defined the post-burn time interval until the beginning of the laboratorial analysis. The time interval varied from $7 \mathrm{~s}$ to four weeks. No time interval was mentioned in 22/116 (19\%) of the articles.

\section{Discussion}

Considering advances in burn treatment, which mainly occurred after the second World War, these have included advances in patient fluid therapy, antibiotic therapy, rigorous nutritional control, new types of dressings, bioengineering and early surgical treatment. All these have been important developments; however more still needs to be undertaken. Burn research may be undertaken through cell culture, animal, or human clinical studies.

Cell culture considers aspects of cell and molecular biology under different conditions, providing an efficient model for the study of physiopathology. It is possible to develop tissue bioengineering and research burns on them, including developing new materials to treat a diverse range of cutaneous lesions ${ }^{22,23}$. Improving bio-molecular understanding and therefore accelerating the development of new therapies is also an advantage of this process. The disadvantage is that after a continuous period of growth, the cellular characteristics may change and become different to that of the donor including, and it has a lack of neuroendocrine signaling in relation to experimental animals ${ }^{24,25}$.

Regarding clinical studies with humans, the central focus is concerning ethical issues and bio-ethics respectively. The advantages and disadvantages are clearer than in other studies when humans are used as experimental models. Another consideration relates to the need to have a significant number of patients where many variations exist between patient types and that of trauma in order to obtain significant results.

Animal research improved by control during procedures, anesthetic and animal production that could be present human pathologies $^{26}$. From the resolution number 196/96 of the National Health $\mathrm{Council}^{27}$, there was a regulation of research, teaching and extension involving animals. Therefore, various educational institutions have installed the Ethics Committee, and that research involving animals must conform to ethical and scientific standards to enable them to progress to the research ${ }^{26}$.

The choice of suitable methods for sedation, induction of anesthesia and pain control, especially in the postoperative period, is vital in experiments involving animals. Burns are considered condemnable experiments to cause intense suffering, physical and mental. The experiments that may cause pain or distress should be developed under adequate sedation, analgesia or anesthesia, being forbidden the use of neuromuscular blocking agents or 
muscle relaxants in replacement of substances sedative, analgesic or anesthetic ${ }^{26,28}$.

Studies involving animals allows research to be undertaken in the areas of physiopathology, histology and molecular events through time; testing prophylactic and therapeutic treatments in burns, including making this knowledge available for further clinical studies. Some animals such as rats, mice, hamsters, rabbits, pigs, sheep and dogs, have been used as study-models for understanding the stages of healing; the use of these animals, however, is not universal ${ }^{29}$. Such studies have the advantage of presenting physiological and pathological characteristics similar to those of humans, considering stimulus to the nervous, cardiovascular, endocrine, and immunological systems.

The rat has many advantages in that it is small, allowing ease of handling. They are also cheap and have a high reproductive rate. However, their disadvantages include those of their differences when compared to human i.e. size, metabolic characteristics and anatomy ${ }^{30}$.

The pig is the animal which is closest to humans in terms of some characteristics such as metabolism and structure of the skin; however, cost-benefit considerations show that they are more demanding in terms of investment and their use is more complicated, besides this, they have a greater risk of infection, demanding greater care and expenditure ${ }^{31}$.

This study had as its objective, to review the literature concerning experimental models using rats, burns and its characteristics. Throughout the research we attempted to provide greater detail concerning the main aspects and peculiarities of many variables that were considered as main health-disease-recovery process indicators. After selecting the cases and after the literature review we were able to observe that there was no standardization in the articles researched. This reflects the specialized periodicals and their editorial board's lack of knowledge regarding many aspects of burns research, as they accept for publication many papers that are incomplete and missing valuable information.

Regarding the techniques for producing burns, the hot water model was used the most. The hot liquid is the most frequent cause of burns in children, mainly those under five years of age. Hot water is also easy to use for animal experiments. When working with animals, spilling is not an adequate procedure to produce burns, as this limits the control of the area to be burnt. Special stages must be followed and proper handling of equipment must be structured as to allow for total control of burn production in accordance to research needs.

Even though hot liquid is the most used resource in animal research, the most prevalent agent for producing burns in Brazil is liquid alcohol, with an average of $30 \%$ for different burn centers. This is the case in Brazil due to the ease of access to liquid alcohol found in large volumes in plastic containers, in any supermarket throughout the country, and mainly used for cleaning and lighting barbecue. Due to the ease of access to alcohol in Brazil, many accidents resulting in burns of various types and degrees are common. Alcohol was not used as a model for producing burns in rats in the articles researched, indicating that the research was carried out in countries where this agent is not easily found and also due to the difficult control conditions regarding burn production mainly control of thickness and size when using alcohol ${ }^{32}$.

Regarding the size and thickness of burns, the majority of studies specified these issues and the relevance. The great majority of studies researched second and third degree burns. The size of the burns varied greatly, each varying according to the main objectives of the research. A $60 \%$ burn area however, provides a great risk of death for animals and these cases were studies for evaluating results for immediate post-burn conditions. In burns performed with instruments, the area varied according to the shape and size of the tip of the instrument.

Dealing with the location of the wound, the back was the choice in most cases, perhaps due to its size and difficulty for the animal to provoke further injuries to the wound, as it very difficult for the animal to lick or scratch the back. Due to the risk of the animal rubbing itself against the wall of the cage and further damaging the produced burn it is necessary to use primary and secondary dressings over the wounded area using an antibacterial agent or placebo. The abdominal region of the animal must be avoided due to the fact that it is easy for the animal to reach this region by licking and even leading to mutilation of the affected region.

Anesthetics were widely used in the experiments. In relation to the use of analgesia during the postoperative period, more than half of the articles did not mention the use of any type of analgesic. The postoperative period is a fundamental stage in the clinical treatment of burns, where the treatment of pain has an important role in the overall clinical evolution; it is therefore surprising to have no detailed information concerning analgesia. Regarding the use of non-steroid analgesics in burn patients, these are not used due to possible renal complications and gastrointestinal bleeding. Steroids, are not used as they diminish burn patients' immunity, which is already compromised, and also due to the risk of gastrointestinal bleeding. Opiate derived analgesics however, are more appropriate for animal models presenting extensive 
burns, stronger opiates for extensive burns and weaker opiates for less extensive burns. For the research ethics the lack of use of analgesics to animal is an important point to refuse paper.

The fluid therapy of animals during the postoperative period was performed as a routine procedure. More than half of the studies used this therapy, indicating the importance of this procedure for experiments with later evaluation - this related to third degree burns and burns of large surface areas - as was the case when a $60 \%$ burn area was produced, generating great hemodynamic instability as in clinical conditions ${ }^{33-35}$.

As for the use of topical antimicrobial, the majority of studies made no mention regarding their use. When it was mentioned, the use of antimicrobial containing silver was described. This is considered nowadays, the best option for wound treatment in order to reduce the proliferation of microorganisms and hence infection ${ }^{36}$.

Considering our findings, therefore, in the majority of studies the entire normal burn sequence from burn up to postoperative clinical treatment was not described. The causal agent related to the study research question, the part of the body affected, the preparation of the area by depilation, the anesthetic procedure, the time-period and intensity of contact between the burn agent and the animal, the definition of thickness and size of burn to be produced, the study of local and systemic effects, dressings and postoperative care, analgesia, fluid therapy, care of wound, time-period after burn to conduct study and register findings, type of data that must be collected, procedure to undertake euthanasia, statistical analysis - all these factors, issues and considerations must be part of the burn research and its planning stage for clinical treatment.

The methodology is the fundamental chapter when performing experimental studies. In this chapter the author presents the main procedures that took place in conducting the research. The descriptions must provide all details, avoiding the "non-information trap". Only following strict rules and offering detailed information the experiments will be replicable. By doing so, this will characterize a high research quality and ethics and the reward for this should be the possibility to publish in high journals quality. The editorial boards of specialized journals must be prepared to consider many relevant details for burns research. This is the only way to allow for greater use of research in real-life cases and for improving future research.

\section{Conclusions}

The hot water is the main method to produce third degree burns to the back, using ketamine associated with xylazine as anesthesia following depilation with appropriate equipment. Results are evaluated via microscopy, without evidence concerning the use of analgesia or antimicrobial during the postoperative period while involving fluid therapy. Incomplete details were found in the selected articles concerning the used methodology, allowing us to conclude that studies on cutaneous burns in rats are not easily replicable.

\section{References}

1. Brigham PA, McLoughlin E. Burn incidence and medical care use in the United States: estimates, trends, and data sources. J Burn Care Rehabil. 1996;17(2):95-107.

2. http://www.ameriburn.org.

3. McCaig LF, Burt CW. National Hospital Ambulatory Medical Care Survey: 2002 emergency department summary. Adv Data. 2004;18(340):1-34.

4. Organization WH. The Global Burden of Disease: 2004. Geneva2008; Available from www.who.int/healthinfo/global burden_disease/GBD report_2004update_full.pdf.

5. Ashburn MA. Burn pain: the management of procedure-related pain. J Burn Care Rehabil. 1995;16(3 Pt 2):365-71.

6. Rosenkranz KM, Sheridan R. Management of the burned trauma patient: balancing conflicting priorities. Burns. 2002;28(7):665-9.

7. Summer GJ, Puntillo KA, Miaskowski C, Green PG, Levine JD. Burn injury pain: the continuing challenge. J Pain. 2007;8(7):53348.

8. Hawkins A, Maclennan PA, McGwin Jr G, Cross JM, Rue LW, 3rd. The impact of combined trauma and burns on patient mortality. J Trauma. 2005;58(2):284-8.

9. Corry NH, Klick B, Fauerbach JA. Posttraumatic stress disorder and pain impact functioning and disability after major burn injury. $\mathrm{J}$ Burn Care Res. 2010;31(1):13-25.

10. Taal LA, Faber AW. Burn injuries, pain and distress: exploring the role of stress symptomatology. Burns. 1997;23(4):288-90.

11. Iurk LK, Oliveira AF, Gragnani A, Ferreira LM. Evidências no tratamento de queimaduras. Rev Bras Queimaduras. 2010;9(3):959.

12. Gragnani A, Ferreira LM. Pesquisa em queimaduras. Rev Bras Queimaduras. 2009;8:91-6.

13. Holmes JHT. Critical issues in burn care. J Burn Care Res. 2008;29(6 Suppl 2):S180-7.

14. Horton JW. Left ventricular contractile dysfunction as a complication of thermal injury. Shock. 2004;22(6):495-507.

15. Longarela A, Olarra J, Suarez L, Garcia de Lorenzo A. Metabolic response to stress, can we control it?. Nutr Hosp. 2000;15(6):275-9.

16. Herndon DN, Tompkins RG. Support of the metabolic response to burn injury. Lancet. 2004;363(9424):1895-902.

17. Gore DC, Chinkes D, Heggers J, Herndon DN, Wolf SE, Desai M. Association of hyperglycemia with increased mortality after severe burn injury. J Trauma. 2001;51(3):540-4.

18. Ferreira LM, Hochman B, Barbosa MV. Experimental models in research. Acta Cir Bras. 2005;20(Suppl 2):28-34.

19. Hillmer MP, MacLeod SM. Experimental keloid scar models: a 
review of methodological issues. J Cutan Med Surg. 2002;6(4):3549.

20. Rosenthal N, Brown S. The mouse ascending: perspectives for human-disease models. Nat Cell Biol. 2007;9(9):993-9.

21. Mesquita CJG, Leite JAD, Fechine FV, Rocha JLC, Leite JGS, Leite Filho JAD, Barbosa Filho RA. Effect of imiquimod on partialthickness burns. Burns. 2010;36(1):97-108.

22. Supp DM, Boyce ST. Engineered skin substitutes: practices and potentials. Clin Dermatol. 2005;23(4):403-12.

23. Sobral CS, Gragnani A, Cao X, Morgan JR, Ferreira LM. Human keratinocytes cultured on collagen matrix used as an experimental burn model. J Burns Wounds. 2007;7:e6.

24. Gragnani A, Morgan JR, Ferreira LM. Experimental model of cultured skin graft. Acta Cir Bras. 2004;19(Special Edition):4-10.

25. Gragnani A, Morgan JR, Ferreira LM. Experimental model of cultured keratinocytes. Acta Cir Bras. 2003;18(Special Edition):4-14.

26. Schanaider A, Silva PC. Uso de animais em cirurgia experimental. Acta Cir Bras. 2004;19(4):441-7.

27. Resolução $n^{\circ} 196$ do Conselho Nacional de Saúde.

28. Colégio Brasileiro de Experimentação Animal. Disponível em http://www.cobea.org.br/

29. Ramos M, Gragnani A, Ferreira LM. Is there an ideal animal model to study hypertrophic scarring? J Burn Care Res. 2008;29(2):363-8.

30. Gould LJ, Leong M, Sonstein J, Wilson S. Optimization and validation of an ischemic wound model. Wound Repair Regen. 2005;13(6):576-82.

31. Santos Heredero FX, Hamann C, Obispo Martin JM, Rodriguez Arias C, Coca Menchero S. Experimental burn models. Ann Burns Fire Dis. 1996;9(2):96-100.

32. Lacerda L, Oliveira AF, Gragnani A, Ferreira LM. Estudo epidemiológico da Unidade de Tratamento de Queimaduras da Universidade Federal de São Paulo. Rev Bras Queimaduras. 2010;9(3):82-8.

33. Oliveira HM, Sallam HS, Espana-Tenorio J, Chinkes D, Chung DH, Chen JDZ, Herndon DN. Gastric and small bowel ileus after severe burn in rats: the effect of cyclooxygenase- 2 inhibitors. Burns. 2009;35(8):1180-4.

34. Jeschke MG, Gauglitz GG, Song J, Kulp GA, Finnerty CC, Cox RA, Barral JM, Herndon DN, Boehring D. Calcium and ER stress mediate hepatic apoptosis after burn injury. J Cell Mol Med. 2009;13(8B):1857-65.

35. Barber RC, Maass DL, White DJ, Horton JW. Increasing percent burn is correlated with increasing inflammation in an adult rodent model. Shock. 2008;30(4):388-93.

36. Wasiak J, Cleland H, Campbell F. Dressings for superficial and partial thickness burns. Cochrane Database Syst Rev. 2008(4):CD002106.

\section{Correspondence:}

Prof. Alfredo Gragnani

Rua Napoleão de Barros, $715 / 4^{\circ}$ andar

04024-002 São Paulo - SP Brasil

Tel.: (55 11)5576-4118

alfredogf@ig.com.br

Received: January 10, 2012

Review: March 12, 2012

Accepted: April 16, 2012

Conflict of interest: none

Financial source: Institutional Program for Scientific Initiation Scholarships of UNIFESP/EPM

${ }^{1}$ Research performed at Department of Surgery, Division of Plastic Surgery, Federal University of Sao Paulo, Paulista School of Medicine (UNIFESP-EPM), Brazil. 